\title{
Face to Face vs. Online Instruction: An Analysis
}

\section{Sujatha. $U^{1}$, Bhuvaneshwari Palanisamy ${ }^{2}$}

Department of English, Saveetha Engineering College, Chennai, Tamil Nadu, India

\begin{abstract}
The role of instructors in face to face and online instruction has few things in common but many things in contrast. Other than the strong foundation of knowledge, traditional classroom teachers have more responsibilities like adaptability, motivating and encouraging active participation, listening to students, enhance collaboration with other students, etc. Traditional classroom teachers create a new society and an active learning environment for the students inside the classroom whereas the role of online instructors is contravening and never-ending. In online instruction designing a course, content delivery, activities, assignments, and examination are done in the absence of students. The flexibility in online learning, though communication is done through electronic media to an extent, considerably reduces the interaction between the teachers and learners and makes either of them to work in isolation. This paper discusses the advantages, disadvantages, and other aspects of face to face and online learning.
\end{abstract}

Keywords:

traditional classroom, online learning, learning environment, interaction.

Article Received: 18 October 2020, Revised: 3 November 2020, Accepted: 24 December 2020

\section{Introduction}

Technology has marked its footprint, almost in all the industries including education. It has changed the way how the information is delivered to the students and also creates an effective pedagogical strategy that simplifies the task of the teachers. Technology which is integrated into traditional classrooms has overwhelmed it and branched into a new field as online education. Traditional or conventional classroom teaching is a more familiar approach and it is teacher-centered. The teacher takes full control over the class and undertakes various responsibilities like presenting materials, conducting the activity, and assessing the students. Here, the students play a passive role like listening to the teacher and try to understand or follow the ideas or instructions delivered by the teacher. Even though online resources like video, audio, etc are used in the traditional classroom, they act as supporting material for the teacher and the essence of the traditional classroom remains the same. In online instruction, the teacher is the authority of the classroom but plays the role of a guide, a facilitator, or a coach rather than a teacher. Online education is student-centered, where the facilitator remains passive but the students play an active role. The responsibility of a teacher does not end with just giving instruction and material to the students; they emphasize more interaction, collaboration, and active participation. Online Vs face to face Instruction

Though the role of the teacher appears to be similar in both contexts, they are contradictory in various aspects. Teaching face-to-face and teaching online are both teachings, but they are qualitatively different. In comparison, driving a car and riding a motorcycle are both forms of transportation, but they have enough differences to warrant additional training and preparation when switching from one to the other. The same is true when faculty move from the traditional classroom to the online classroom. [1]

In online teaching, the teacher plans and designs all the units prior to the course with required resources like audios, videos, practice exercises, etc and directs the students to the resources, and guides them to understand the concepts of the course. They have to contribute more time in preparing the materials as well as to make the learners be attentive and manage to retain the interest in the course till the end. As everything is documented in online teaching the teacher should keep track of materials viewed by each student, assignment submission status, and participation in the discussion forum in the online platform itself. 
Traditional classroom teachers also do similar work but with certain changes. Planning and preparation for the units, resources, and teaching is done simultaneously.

Online teaching takes place in isolation, where students are likely to get distracted and tend to lose interest in the course. In such cases, teachers undertake another burden of encouraging the students with constructive and positive feedback to stimulate the learning interest within the student. The teacher has to travel along with the student on the journey of the course to maintain and uphold the interest in the course. In a traditional classroom, students are physically present together with their friends and the teacher keeps the students attentive with well structured and interesting lessons. The understanding level of each student can be determined by formative assessment and interacting session.

The prevalent availability of online resources provides innumerable material to the students to explain the concepts which provoke the students to learn everything by themselves. In such situations, students get deviated and go out of control of the teachers. As a solution, teachers have to be experts in their area and prepare unique accessible materials with convincing quality. But traditional classroom teachers are the sole resource of knowledge which they disperse as a monologue in front of the students. Students listen to it and get benefited by writing notes, memorizing, and learning them. The teacher can encourage interaction with them and face-to-face peer-discussion.

Traditional classrooms are knowledge-based where teachers focus on imparting knowledge to the students and to be more competent in using digital and modern technologies. They teach how technology can be used in most modern or advanced methods, especially electronic equipment and computers. But in online classes, the process of educating is carried out only through the support of technology. Ideas that are merely observed as the theory in the traditional classroom are implemented practically in an online classroom.
Advantages of online Instruction:

Various advantages of online teaching draw the attention of teachers, professionals, and subject experts towards this profession.

- The massive collections of online tools and resources like Google classrooms, Zoom, Google docs, Prezi, Coursera, etc available in the online platform, helps the teachers to design the lesson plan beyond the textbook limitation. The extensive usage of online resources and the use of digital tools improve the efficiency of the teachers in the online classroom. Since the online lecture can be recorded and shared for future use, it refrain the teachers from reworking on the same topic.

- Flexibility in time and place is the major advantage of online teaching. Teachers need not travel all the way to reach the institution or organization for taking the class. Either it's synchronous or asynchronous teaching the teacher can decide a convenient time for scheduling the class. Online instruction takes place beyond the geographical limitations and allows the teachers to take classes from any location and time of their choice.

- Online teaching is not time-bound so it provides teachers with more teaching opportunities and freedom to handle a variety of courses at the same time.

- The progress of every student on the periodic test, quiz, grades, etc is auto documented in the online line platform; it saves time and works in organizing the administration of the class so that teachers can concentrate more on performance and approach of teaching.

- Online teaching provides one to one and group conservation opportunities to the teachers. Communication is carried out 0 maximum through online electronic mode 
so that assessment and feedback can be done in a more personalized way. Positive feedback motivates the students to move further and negative feedback prevents the intimidation of students.

\section{Disadvantages of online Instruction}

- Online teachers are committed to satisfying the need for various styles of students. Few students are comfortable studying at their own pace, few students need guidance, and some struggle to focus on the screen for a long period of time. So they often get distracted. Online educators need to undertake a task to prepare and present interesting materials and resources to perpetuate the interest of the students.

- Online instruction is wholly based on internet connectivity. If there is any inconsistency in the connectivity then continuity of the teaching process is entirely affected.

- Peer interaction, discussion, and social skills are very important in a learning environment. This is an added responsibility for the teachers to motivate the students to indulge in discussions and maintain a good level of communication with the teacher and also within the students. Any form of communication like online messages, emails, and video conferencing should be encouraged to reduce the sense of isolation.

- Teachers who have used chalk and talk for presenting the content, have to be techfriendly and train themselves to use all sorts of online tools, materials, and resources to conduct their online class in an effective way.

- Teachers have to keep track of the students and monitor their progress and performance throughout the course. Since teaching takes place in the physical absence of students, teachers have to make frequent communication and motivate students, if they lag or lose interest in the course.

- Teaching is not applicable for the teachers and professionals, whose major are completely integrated with practical and theory. If a student is considering a major in nursing, agriculture, biology, music, or theater, online classes can only get them so far. While it is easy to take some required classes online in these majors, the classes that include labs, clinical practice, or performances cannot be done without a traditional campus class.[2]

\section{Advantages of traditional Instruction:}

On-campus education, which happens in a specific environment, is still believed to be an effective way of the teaching-learning process. Multiple skills that teacher train in the traditional classroom, like social interaction, discipline, punctuality, etc makes traditional classroom to sustain its uprightness in the internet era.

- Traditional teaching is the direct method of teaching, where passionate and enthusiastic teachers create a positive learning environment, which builds confidence among the students and obtain a quality education. Teachers' actions and language become the target imitated by learners, whose outlook towards right and wrong, attitude, value orientation and academic level have great impact on students.[3]

- The physical presence of teachers and students facilitates the teachers to adapt different teaching styles for different students. This approach helps the teachers to incorporate an effective teaching pedagogy. Teachers have preferences like visionary, auditory, and kinesthetic styles, among which they can use any one of them or everything to stimulate the learners' interest over the subject and make their class as interactive as possible. 
- The responsibility of the traditional classroom teachers is combined with teaching as well as mending the students. The face to face approach in traditional classrooms enables the teachers to discern the caliber of every student and segregate the slow learners. These students can be given extra attention to cope up with other students.

- Teacher-student face to face interaction is the major advantage of the conventional classroom. The content, which is taught through active participation of the students inside the classroom along with the constant feedback of the teacher, will reach the students better than passive listening to lectures in online learning.

- A fixed schedule and specific timetable followed in a traditional classroom help the teachers to be more focused on the topics covered and monitor the work assigned to the students. This practice deprives the students from procrastination of the work assigned to them after every lecture and improves self-discipline.

\section{Disadvantages of traditional Instruction}

- Traditional teaching is a teacher-centered approach and designed to engage with the curriculum. It concerns more on repetition and memorizing the content and passes the examination with better grades. This makes the students more dependent on prescribed notes and lacks certain skills like problem-solving and analytical thinking. Students do not understand the need for the course and benefit of the learning the subject. This affects the learning outcome of the program.

- The traditional teaching model is a oneway communication process and there is no active participation of the listeners. The efficiency of the teacher is measured by their ability to complete the course on time and by conducting more tests and make the students score high in their subjects. This reflects on the students with a lot of psychological pressure. The teacher presents the content in front of the class but cannot pay attention to everybody in class at the same time. To rectify this, teachers have to take intense action to show concern over every individual student in the class and motivate them to maintain interest in the subject.

- In the traditional teaching method, the teachers simplify and present the content to the level of the students, which makes them more dependable on prescribed notes and texts. It limits the thinking capacity of the students that are required to understand complex ideas to sustain lifelong learning. The knowledge is limited; the resource is scarce; the learning is passive but the knowledge is well-formed and departed from real life. The main experience is insufficient or lack of subjective experience, which will restrict the effectiveness of learning strategy teaching.[3]

- Time constraint is the major disadvantage of traditional teaching. Teachers have to follow strict schedule designed by the organization. This approach restricts the teachers to conduct hands-on training and classroom-based activities for all the students during class hours. Much of the class hours are contributed for presenting and little time In such cases introverted students would hesitate and do not participate in the activities and would lag behind. This strategy does not allow for students to experiment with new concepts. Their learning is put to a halt at a certain stage; they end up cramming concepts, and are unable to produce anything fruitful, except generic answers to exam questions. [4] It is a challenging task for the teachers to maintain a balance in handling students equally.

- The evaluation process in the traditional classroom is time-consuming and 
toilsome. Teachers have to manually grade the assignments and test papers for every class and publish the results. This makes the students to receive a delayed feedback.

\section{Conclusion}

Traditional teaching methodology, with its rigid structure and design, has benefited students for centuries. In a long run, the time has marked changes in the field of education, due to the massive impact of technology. This change demands the teachers to change the methodology of teaching and articulate a different pedagogy to equip the students to survive in the modern competitive world. Online teaching stands as the best alternative for those, who were discontented with the disadvantages of the traditional teaching model. The online teaching model offers the teachers to expand their knowledge in their field and adjust themselves to the advancement of technology. But this model cannot eliminate the conventional model and replace it. It has taken a parallel place in the education field. As digital immigrants teachers change their role as facilitator or a coach and enjoy the advantage of technology but have to change every aspect of teaching like curriculum, methods of teaching, delivering content, etc to fulfill the needs of digital natives. Traditional classroom teachers shape the students socially, emotionally, and psychologically in the physical classroom environment and also adopt various technological tools inside the classroom but still within the boundary of the time limit.

\section{References}

[1] [1] Bull EdD, Bernard. "Eight Roles of an Effective Online Teacher." Faculty Focus. 3 June.

2013, https://www.facultyfocus.com/articles/onlineeducation/eight-roles-of-an-effective-onlineteacher/\#: :text=Similarly\%2C\%20the $\% 20$ o nline $\% 20$ teacher\%20plays,and\%20less $\% 20$ ti me\%20preparing\%20lessons.

[2] [2]University of POTOMAC. Top 6 Advantages of Traditional Education.(n.d) Retrieved https://potomac.edu/topadvantages-of-traditional-education/
[3] [3] Liu,Chunyang \& Long,Fei. The Discussion of Traditional Teaching and Multimedia Teaching Approach in College English Teaching.(2014), file://C:/Users/user/Downloads/11134\%20(1 ).pdf

[4] [4] Progress Educat. Three Disadvantages of Traditional Classroom Learning.(n.d), Retrieved http://eldevenirneocoach.blogspot.com/2012/07/threedisadvantages-of-traditional.html

[5] Bates, Tony. "Nine steps to quality online learning: Step 1: Decide how you want to teach online."Online learning and distance education resources.6 May. 2012, https://sites.google.com/a/hawaii.edu/new-defaculty-orientation/Step-1

[6] Dani, Vishal. Kitaboo. Is Online Education Better than Traditional Education? 30 January. 2019, https://kitaboo.com/is-onlineeducation-better-than-traditionaleducation/\#: :text=In\%20a\%20traditional $\% 2$ 0teaching\%20model,peer\%2Dto\%2Dpeer\%2 0collaboration.

[7] EU Blog. The Role of the Teacher in the Digital Age. 10 December 2020, Retrieved https://www.euruni.edu/blog/future-profonline-learning/

[8] Fedena. Advantages and Disadvantages Of Online Learning. 5 October 2020, Retrieved https://fedena.com/blog/2020/10/advantagesand-disadvantages-of-online-learning.html

[9] Gosh, Robbin. Victorious Kidss Educares. Impact of Technology on Education. 4 February. 2013, https://www.victoriouskidsseducares.org/imp act-of-technology-on-education/

[10] Jaebi.Classroom. Disadvantages of Traditional Classroom Training.(n.d), https://classroom.synonym.com/disadvantage s-traditional-classroom-training7866705.html

[11] Lathan, Joseph. University of San Diego. Complete Guide to Teacher-Centered vs. Student-Centered Learning.(n.d), https://onlinedegrees.sandiego.edu/teacher- 
centered-vs-student-centered-

learning/\#: :text=teacher-

centered $\% 20$ educational $\% 20$ approach $\% 2 \mathrm{C} \%$

20the, is \%20the $\% 20$ sam

[12] Montgomery College. ADVANTAGES AND DISADVANTAGES OF ONLINE

COURSES. (n.d), Retrieved

https://www.montgomerycollege.edu/academ ics/online-learning/distance/advantages-anddisadvantages-online-courses.html

[13] Palmer, Maggie. Bridge Universe. Teaching Online vs. the Classroom - How Do They Compare? 26 February 2020, https://bridge.edu/tefl/blog/teaching-onlinevs-classroom/

[14] Santos, Barbara. Hotmart Blog. What is the role of an online teacher? 2 November. 2018,https://blog.hotmart.com/en/role-of-anonline-teacher/

[15] UrbanPro. Top 10 Benefits of Online Teaching. (n.d) Retrieved https://www.urbanpro.com/onlinetutoring/top-10-benefits-online-teaching 